\title{
Régimen jurídico del cambio de denominación municipal en el Derecho Autonómico valenciano*
}

\author{
Rafael D. Agulló Mateu \\ Licenciado en Derecho, Licenciado en Ciencias Políticas \\ y de la Administración \\ Diplomado en Gestión y Administración Pública
}

Sumario: I. DENOMINACIÓN MUNICIPAL Y POLÍTICA LINGÜÍSTICA. I.1. El nombre de los lugares y su significación simbólica. I.2. La denominación municipal como instrumento de normalización lingüística. I.3. Diferentes regímenes autonómicos en materia de cambios de denominación Municipal. II. CAMBIO DE DENOMINACIÓN DE LOS MUNICIPIOS DE LA COMUNIDAD VALENCIANA. Procedimiento Administrativo. II.1. Competencias normativas. II.2. Régimen jurídico aplicable al cambio de denominación de los municipios Valencianos. III. CONCLUSIONES. IV. BIBLIOGRAFÍA.

\section{DENOMINACIÓN MUNICIPAL Y POLÍTICA LINGÜÍSTICA}

\section{I.1. El nombre de los lugares y su significación simbólica}

La denominación de los lugares, en especial la de aquellos que han sido largamente habitados, trasluce las huellas que el tiempo, la tradición y las edades antiguas dejaron en ellos. El modo en que estos parajes son identificados, contiene un fuerte simbolismo que aglutina y une bajo él a todos los habitantes, presentes, pasados y futuros, que transitaron por unas mismas calles, disfrutaron de unas mismas tradiciones, $y$, en definitiva, formaron una misma comunidad que ha asistido unida, y bajo un nombre igual, al paso de los años. Como indicara Menéndez Pidal ${ }^{1}$, la necesidad diaria de nombrar este terruño une a través de los milenios la pronunciación de los habitantes de hoy con la pronunciación de los primitivos.

Los topónimos, entendidos en el sentido que lo hace la Real Academia de la Lengua, como el nombre que le es propio a un lugar, oculta tras de sí una concepción ideológica y heterogénea, por cuanto la pronunciación del mismo trae a la mente del interlocutor, una serie de pensamientos y convenciones

\footnotetext{
* Trabajo galardonado en el I Premio Civil sobre Régimen Local, organizado por la Conselleria de Justicia y Administraciones Públicas de las Generalitat Valenciana.

${ }^{1}$ R. MENÉndeZ PidAL, Toponimia prerrománica hispánica. Ed Gredos. Madrid 1952, p. 5.
} 
sobre las gentes, las costumbres, el clima o el entorno de una población, extremos todos ellos que quedan, de una forma casi mágica, contenidos dentro de unas pocas letras cuyo orden fue determinado por algún lance de la historia.

Dado el carácter representativo con que cuentan las denominaciones de pueblos, territorios y Estados, se ha producido un curioso fenómeno que ha provocado que uno de los elementos de lucha y reivindicación de lo propio, se haya articulado, precisamente, a través del modo en que son conocidos los lugares. Así, lo que en ocasiones no ha sido más que una adaptación a la lengua del conquistador del territorio adquirido tras la lucha, fue otras veces un modo de demostrar la supremacía del vencedor, llegando, en casos extremos, a convertirse en una forma de esterilización cultural, pretendiéndose eliminar todo vestigio del enemigo vencido.

Como claro ejemplo de esta última afirmación, pueden traerse a la memoria los fenómenos de persecución que la cultura y usos de los territorios incluidos en la antigua Corona de Aragón sufrieron tras el final de la Guerra de Sucesión, acaecida en el siglo XVIII. Tras su victoria, Felipe V de Borbón, dispuso una serie de decretos, denominados de Nueva Planta, que pretendían establecer un nuevo sistema político-administrativo, consistente en implantar el modo de gobierno de Castilla sobre la tradición jurídica, cultural y lingüística de los reinos vencidos. Una de las más claras manifestaciones de esta intención de conquista y eliminación de lo anterior, fue la destrucción de la ciudad de Xàtiva, perteneciente al Reino de Valencia, la cual había opuesto una feroz resistencia a las tropas borbónicas. La acción consecuente ante tal resistencia, no se limitó a reducir a cenizas la ciudad, sino que, ante un icono de oposición armada como fue Xàtiva, se reaccionó también con un acto cargado de simbolismo, procediéndose al cambio de denominación de la población reconstruida, la cual, no sólo perdió su denominación en la lengua propia, sino que pasó a denominarse Colonia Nueva de San Felipe².

Actos de persecución como éste, consistentes en el ataque a los símbolos, como son las instituciones, la bandera o la lengua del otro, se han producido en no pocas ocasiones, lo cual, unido a otros medios más sutiles de descrédito, como la no enseñanza oficial de la lengua propia, o la expulsión del sistema legal de las normas y los usos tradicionales del territorio, han supuesto una importante pérdida de identidad de los pueblos.

En la historia de nuestro país, contamos con no pocos ejemplos de este tipo de comportamientos. De hecho, salvando el corto período de resurgi-

2 E. GIMÉNEZ LóPEZ, Gobernar con una misma ley: sobre la nueva planta borbónica en Valencia. Ed Univ Alicante. Alicante 1999. p. 68. 
miento de las sensibilidades políticas de las distintas nacionalidades que tuvo lugar durante la Segunda República, momento en que fueron incluso plebiscitados Estatutos de Autonomía por parte de Cataluña, Galicia y País Vasco, quedando en preparación otros como el Valenciano, se ha asistido, dentro de nuestras fronteras, a una constante de desconocimiento y menosprecio, tanto social, como jurídico-administrativo, de las lenguas y culturas distintas a la reconocida por el Gobierno central.

Por ello, ante el advenimiento de la democracia en la España de finales de los años 70, tras otra larga época de restricciones y persecución de las distintas nacionalidades que concurrían en el Estado, se asistió a un renacimiento y nueva reivindicación de las culturas oficialmente aletargadas por medio de leyes y comportamientos sociales, constituyéndose como verdadero punto de inflexión el tenor del artículo 2 de la Constitución ${ }^{3}$, en el cual se reconocían de forma abierta las distintas nacionalidades que conforman el Estado Español. Se abrió así un nuevo período en el que las culturas y lenguas gallegas, vascas, catalanas, y valencianas, entre otras, hasta entonces degradadas y oprimidas, volvían a cobrar un protagonismo hurtado históricamente por consideraciones políticas.

En esa época de cambios, pronto fue materializándose, por medio de la articulación del Estado Autonómico, una verdadera inquietud por el redescubrimiento de lo autóctono, de forma que los nuevos entes territoriales dieron especial importancia al reconocimiento y oficialización de sus elementos singulares. Entre dichos elementos, y por lo que respecta a aquellas Comunidades Autónomas que contaban con un idioma propio suficientemente desarrollado, cobró especial importancia la recuperación del mismo, el cual, en la mayoría de los casos, aunque había continuado su uso de forma más o menos habitual, se encontraba fuertemente desestructurado y fuera de toda utilización oficial o educativa.

Ante esta realidad, se pusieron en marcha distintas iniciativas de reivindicación de la lengua, siendo la más importante la recepción, en los respectivos Estatutos de Autonomía, del tenor del artículo 3 de nuestra Carta Magna, en la que se determinaba que, aún siendo el castellano la lengua oficial del Estado, se reconocía la cooficialidad de las demás lenguas españolas en las Comunidades Autónomas que así lo determinasen vía estatutaria.

\footnotetext{
3 Artículo 2 CE «La Constitución se fundamenta en la indisoluble unidad de la Nación española, patria común e indivisible de todos los españoles, y reconoce y garantiza el derecho a la autonomía de las nacionalidades y regiones que la integran y la solidaridad entre todas ellas».
} 
Y así ocurrió, por ejemplo, en el Estatuto del País Vasco ${ }^{4}$, cuyo artículo 6 determina que, «el euskera, lengua propia del Pueblo Vasco, tendrá, como el castellano, carácter de lengua oficial en Euskadi». También se recogió esta idea en la norma básica gallega ${ }^{5}$, la cual, en su artículo 5.1 señala que, «la lengua propia de Galicia es el Gallego», añadiendo en el 5.2 que «los idiomas gallego y castellano son oficiales en Galicia». Igualmente se hizo por parte de la Comunidad Valenciana ${ }^{6}$, en cuyo artículo 7 puede leerse que, «los dos idiomas oficiales de la Comunidad Autónoma son el valenciano y el castellano. (...) La Generalidad Valenciana garantizará el uso normal y oficial de las dos lenguas».

En unos términos similares se expresaron otras Comunidades Autónomas como Navarra ${ }^{7}$, Cataluña ${ }^{8}$ o Illes Balears ${ }^{9}$, siendo ello claro indicativo del espíritu de reivindicación de la lengua autóctona que latía en el ánimo de los estatuyentes, lo que llevó, en el caso concreto de Illes Balears, a establecer como única denominación oficial de la Comunidad Autónoma la hecha en catalán.

La declaración de cooficialidad de las lenguas propias, supuso una serie de efectos sobre el régimen legal y administrativo que los nuevos ejecutivos y legislativos regionales debían afrontar con suficiente previsión. Se les presentaba un auténtico reto de trascendencia histórica, por cuanto había sido puesto en sus manos la posibilidad de traer de nuevo a la vida pública la, en otros tiempos, denostada lengua vernácula.

La normalización lingüística quedó, de este modo, configurada como el ariete o la punta de lanza de la recuperación de las culturas y tradiciones de los territorios. Pero dicha normalización, que afectaba a extremos tan diversos como la educación, los medios de comunicación, o, incluso, la vuelta a las denominaciones tradicionales de instituciones y lugares, requería de unos instrumentos lo suficientemente bien articulados como para permitir que el compromiso social, y con la historia, fuese realmente cumplido.

\footnotetext{
4 LO 3/1979, 18 de diciembre, Estatuto de Autonomía para el País Vasco

5 LO 1/1981, 6 de abril, Estatuto de Autonomía de Galicia.

${ }^{6}$ LO 5/1982, 1 de julio, Estatuto de Autonomía de la Comunidad Valenciana.

7 LO 13/1982, 10 de agosto, de Reintegración y Amejoramiento del Régimen Foral de Navarra, art. 9.2 .

${ }^{8}$ LO 4/1979, 18 de diciembre, Estatuto de Autonomía de Cataluña, art. 3.

${ }^{9}$ LO 2/1983, 25 de febrero, Estatuto de Autonomía de Illes Balears, art. 3.
} 


\section{I.2. La denominación municipal como instrumento de normalización lingüística}

Ante la necesidad de lograr herramientas suficientemente eficaces que permitiesen llevar a cabo la labor de retorno y valorización de las lenguas propias, se aprobaron diferentes leyes autonómicas que pretendían la normalización de sus idiomas propios. En este conjunto de textos legales se encontraban, la Ley Vasca 10/1982, de 24 de noviembre, Básica de Normalización del Uso del Euskera; la Ley 7/1983, de 18 de abril, de Normalización Lingüística Catalana, posteriormente derogada por la Ley 1/1998, de 7 de enero, de Política Lingüística; la Ley Gallega 3/1983, de 15 de junio, de Normalización Lingüística; la Ley 4/1983, de 23 de noviembre, de Uso y Enseñanza del Valenciano; la Ley Balear 3/1986, de 19 de abril, de Normalización Lingüística; y la Ley Foral 18/1986, de 15 de diciembre del Vascuence.

De la lectura de estas leyes se desprende, entre otras conclusiones, que los legisladores autonómicos entendieron la denominación de los municipios de su territorio como una cuestión de primer orden, dado que en la mayoría de las normas lingüísticas, cuando no en los propios Estatutos de Autonomía ${ }^{10}$, se hizo referencia expresa a la necesidad de retornar a las denominaciones históricas de los mismos.

Sirvan como ejemplo de esta última afirmación las siguientes referencias $^{11}$ : el artículo décimo de la Ley Gallega 3/1983, de 15 de junio, de Normalización Lingüística estipula, que «los topónimos de Galicia tendrán como única forma oficial la gallega», señalando en el siguiente numeral que «corresponde a la Xunta de Galicia la determinación de los nombres oficiales de los municipios», concluyendo el tercer apartado que «estas denominaciones son las legales a todos los efectos y la rotulación tendrá que concordar con ellas»; en un sentido similar se expresa el artículo 15 de la Ley 4/1983, de 23 de noviembre, de Uso y Enseñanza del Valenciano, el cual señala que «corresponde al Consell de la Generalidad Valenciana, acorde con los procedimientos legales establecidos, determinar los nombres oficiales de los municipios (..) de la Comunidad. Las denominaciones adoptadas por el Consell serán las legales a todos los efectos».

Gran parte de estos mandatos realizados por las diversas normas lingüísticas, fueron desarrollados posteriormente en procedimientos concre-

\footnotetext{
10 Por ejemplo, el 38.1 del Estatuto Valenciano.

11 En el mismo sentido tenemos el artículo 14.1 de la Ley Balear, el 10 de la norma vasca, o el 18 de la catalana.
} 
tos regulados por medio de leyes o decretos específicos, o bien se incorporaron a la normativa autonómica sobre régimen local. En algunos casos incluso, los procedimientos de cambio de denominación municipal fueron aprobados con anterioridad a la propia la ley de normalización lingüística, lo que evidencia la importancia que este tipo de actuaciones tenían para los nuevos entes autonómicos. Como muestra de normas previas a la de normalización lingüística de la Comunidad, tenemos la Ley Catalana 12/1982, de 8 de octubre, sobre cambio de denominación de municipios, que antecedió en un año a la ley autonómica de normalización, o el Decreto del Consell del País Valenciano de 2 de agosto de 1979, en el cual se asumen competencias sobre la variación de los nombres de los municipios, y se determinan los órganos para su conocimiento y resolución, con casi cinco años de antelación a la ley específica.

Aún existiendo ejemplos de normas anteriores a las leyes de normalización, lo habitual fue que las Comunidades que legislaron al respecto lo hicieran tras la aprobación de las leyes lingüísticas, pudiéndose observar la concurrencia de dos tipos de textos que versan sobre la materia del cambio de denominación municipal. Por un lado estarían aquellas normas que directamente tratan el asunto, desprendiéndose así de su título. Por otro tenemos, como ha sido comentado, la regulación que al respecto se introduce en la legislación sobre régimen local de las respectivas autonomías.

En el primer grupo de textos pueden mencionarse el Decreto 132/1984, de 6 de septiembre, para la fijación y recuperación de la toponimia de Galicia, el Decreto 98/2002, de 18 de julio, sobre procedimiento de recuperación y fijación de la toponimia asturiana, o el Decreto 58/1992, de 13 de abril, del Gobierno Valenciano, por el que se regula el procedimiento para la alteración del nombre de los municipios. Para ejemplificar la segunda alternativa, regulación en la ley de régimen local de la Comunidad, se pueden mencionar los artículos 21 a 23 de la Ley Foral 6/1990, de 2 de julio, de Administración Local de Navarra, o los artículos 30 a 32, del Decreto Legislativo 2/2003, de 28 de abril, por el que se aprueba el Texto refundido de la Ley Municipal y de Régimen Local de Cataluña. En este último caso, en el de la regulación del cambio de denominación en la normativa autonómica sobre régimen local, debe apuntarse que también ha sido utilizada por Comunidades Autónomas sin lengua propia, siendo ejemplo de ello el artículo 6 de la Ley 2/2003, de 11 de marzo, de Administración Local de la Comunidad de Madrid, o el artículo 18 de la Ley 6/1988, de 25 de agosto, de Régimen Local de la Región de Murcia.

Existen por tanto dos modos de abordar el asunto, bien desde una normativa específica, bien desde la legislación genérica sobre régimen local. 
De ello no debe colegirse, sin embargo, que ambas fórmulas sean equivalentes, es decir, pueden apreciarse diferencias sensibles entre una opción legislativa y otra, por cuanto la regulación específica manifiesta un mayor compromiso del poder político de un territorio, y por ende de su ciudadanía, con el objeto de regulación. Afirmación esta que se ve respaldada por la mayor incidencia que las modificaciones de denominación de municipios han tenido en aquellos territorios con norma específica y sobre aquellos otros que no contaban con ella.

La explicación lógica a la relación entre norma expresa sobre cambio de denominación municipal y alto número de renombramientos de municipios no debe entenderse, sin embargo, en el sentido de que tener una específica herramienta sea la causa de que los municipios quieran, en mayor número, variar su denominación, aunque es indudable que una regulación más clara, y referida a órganos de informe y decisión autonómicos, y por tanto más cercanos, no puede por menos que facilitar el procedimiento. Pero, como se decía, la relación entre norma concreta y gran número de cambios de denominación de municipios, se instrumenta en el sentido de que, el legislador autonómico, ante la gran cantidad de peticiones, concretas o previsibles, se ve obligado a dotarse de una normativa que agilice el procedimiento, normativa que no es necesaria en otros territorios donde la existencia de expedientes de ese tipo apenas tiene incidencia.

Entiéndase esta reflexión por medio de datos como los que siguen: el País Vasco, con $250^{12}$ municipios y 110 modificaciones desde 1980, es decir, con una incidencia del $44 \%$ de los municipios, o la Comunidad Valenciana, con 171 cambios y 542 municipios, 31,5\% de incidencia, y ambas Autonomías aún con un importante número de nombres de municipios por adaptar a sus respectivas lenguas, es evidente que tenían más necesidad de una norma específica que, por ejemplo, Castilla La Mancha, que con 919 municipios sólo ha conocido seis expedientes en 25 años, apenas un $0,65 \%$. Téngase en cuenta además, que la necesidad de la norma por el volumen de expedientes era clara en casos como el vasco, donde antes de la aprobación del Decreto correspondiente, que vio la luz a finales de 1983, se habían instruido ya más de sesenta expedientes de cambio de denominación municipal ${ }^{13}$.

\footnotetext{
12 Datos sobre el número de municipios determinados por el INE, en relación a las elecciones generales de marzo de 2004.

13 Decreto 271/1983, de 12 de diciembre, del Gobierno Vasco.
} 


\section{I.3. Diferentes regímenes autonómicos en materia de cambios de denominación municipal}

Una vez esbozado el marco general en el que se sitúa la cuestión sometida a estudio, es momento de dar un paso más y determinar cuales son los distintos regímenes o sistemas de regulación que, dadas las posibilidades arriba señaladas, se han adoptado realmente en el ámbito autonómico. Pasaremos por ello a continuación, a sintetizar las diferentes fórmulas propuestas por los legislativos regionales.

En primer término, tenemos aquellas Comunidades Autónomas que cuentan tanto con norma específica, como con articulado en la propia ley de administración local. Es el caso de Cataluña, que cuenta con la citada Ley 12/1982 sobre procedimiento de cambio de denominación de municipios, la cual, si bien habla de los pasos a seguir por los municipios, versa principalmente sobre el procedimiento en sede gubernativa, dejando la referencias concretas al régimen municipal, en manos de los artículos 30 a 35 , en conexión con el 114.2, del Decreto Legislativo 2/2003, de 28 de abril, por el que se aprueba el Texto refundido de la Ley Municipal y de Régimen Local de Cataluña, y 57 a 60 del Decreto 140/1988 ${ }^{14}$, de 24 de mayo, que aprueba el reglamento de demarcación territorial y población de los entes locales de Cataluña. En un sentido parecido se expresan el Decreto $132 / 1984$, de 6 de septiembre, para la fijación o recuperación de la toponimia de Galicia, y los artículo 48 a 50 de la Ley 5/1997, de 22 de julio, de Administración Local de Galicia. Así también, tenemos el Decreto 98/2002, de 18 de julio, para la fijación o recuperación de la toponimia asturiana, y el artículo 20 de la Ley 10/1986, de 7 de noviembre, reguladora de la demarcación territorial de los concejos del Principado de Asturias.

Existen otras regiones que, careciendo de normativa autonómica sobre Administración Local, aprueban una norma en la que se incluye tanto el procedimiento a seguir por el Ayuntamiento, como el que debe regir la actuación del gobierno autonómico. Tal es el caso vasco, que cuenta con el Decreto 271/1983, de 12 de diciembre, sobre procedimiento de cambio de nombre de los municipios. También este es el caso de la Comunidad Valenciana, cuyo Decreto 58/1992, de 13 de abril, del Gobierno Valenciano, por el que se regula el procedimiento para la alteración del nombre de los municipios, da cumplida cuenta sobre la materia. En ambos textos se explicitan las distintas fases, mayorías, informes y demás elementos del régimen legal aplicable, tanto en sede local, como autonómica.

\footnotetext{
${ }^{14}$ Norma que fue modificada por el Decreto 243/1998, de 22 de septiembre, precisamente en dichos artículos.
} 
Hay un tercer grupo de regiones que cuentan con norma de administración local, pero no con una específica sobre cambio de denominación. Este es, por ejemplo, el caso navarro, cuya ley 6/1990, de 2 de julio, dedica sus artículos 21 a 23 a establecer las obligaciones que conciernen a los municipios que pretendan realizar un cambio en su denominación. En este caso, y por lo que se refiere a la fase gubernativa, simplemente se determina que la solicitud del municipio debe remitirse al Gobierno Foral, el cual resolverá. En este mismo supuesto, de regulación exclusiva en la norma sobre régimen local, se encuentran incluidas la Comunidad de Madrid, art 6 de la Ley 2/2003, de 11 de marzo, de Administración Local de la Comunidad de Madrid ${ }^{15}$; la de Castilla y León, artículos 24 y 26 de la Ley 1/1998, de 4 de junio, de Régimen Local de Castilla y León ${ }^{16}$; la de La Rioja, artículos 23,25 y 26 de la Ley 1/2003, de 3 de marzo, de la Administración Local de La Rioja; la de Aragón, artículos 23 y 25 de la Ley 7/1999, de 9 de abril, de Administración Local de Aragón; y la de Murcia, por medio del artículo 18 de la Ley 6/1988, de 25 de agosto, de Régimen Local de la Región de Murcia.

Por último, encontramos al resto de Comunidades Autónomas, las cuales ni han aprobado norma específica, ni legislación sobre administración local, $\mathrm{o}$, habiéndola aprobado, no se hace en la misma referencia al supuesto de cambio de denominación de municipios. Este hecho no deja de sorprender, al menos en casos como el de Cantabria (art.24.2) o el de Extremadura (art.8.1), cuyos respectivos Estatutos de autonomía recogen, de forma textual, la competencia de dichas autonomías en materia de «alteraciones de los términos municipales comprendidos en su territorio». Pero, sin duda alguna, el caso balear merece un comentario particular, por cuanto presenta ciertas especialidades. En primer lugar vemos que el Estatuto de Autonomía balear recoge, de manera expresa, la competencia en materia de alteración de denominaciones oficiales de municipios (art.10.2). Contamos así mismo con el artículo 14 de la Ley 3/1986, de 19 de abril, de normalización lingüística de esta Comunidad, que se refiere de manera concreta a las competencias del gobierno balear sobre la materia. Pero dichos preceptos, no han sido desarrollados ni legal, ni reglamentariamente, en el sentido de aprobarse una norma que regule el procedimiento a seguir, si bien, sí existe un decreto que determina, de una sola vez, la toponimia oficial de los municipios baleares. Dicho Decreto, que es el 36/1988, de 14 de abril, hace referencia a distintos

\footnotetext{
${ }^{15}$ Debe señalarse al respecto de esta norma que la misma, en el tercer apartado del artículo citado, determina la próxima aprobación de un Decreto que regule, de forma específica, el procedimiento para el cambio de denominación de los municipios madrileños, por lo cual podría casi incluirse en el primer grupo.

${ }^{16}$ Merece destacarse que el artículo 24 de esta norma remite, por cuanto se refiere a ciertas partes del procedimiento, a la legislación nacional.
} 
informes y recomendaciones realizadas por varias instituciones relacionadas con la lengua catalana, como la Universidad de las Islas Baleares, en virtud de las cuales se fijan las denominaciones oficiales. Se da la circunstancia de que dicho Decreto ha sido posteriormente modificado para introducir alteraciones en las denominaciones que establecía, habiéndose realizado la última actualización por medio del Decreto 2/2004, de 16 de enero. La existencia de este listado oficial podría haber supuesto la inclusión de esta Autonomía en el grupo de las que cuentan con norma específica de desarrollo, pero dado el carácter estático de su contenido, que no determina un procedimiento genérico sino que legaliza sin más las denominaciones, hemos preferido referirlo en el grupo de los que carecen de dicha norma ${ }^{17}$.

En cualquier caso, baste decir que, por lo que respecta a este último grupo, la legislación que han aplicado en los supuestos de cambio de denominación que se les han planteado, no ha sido otra que la estatal existente sobre la materia, normativa que también han tenido que aplicar, en mayor o menor medida, la Comunidades del tercer grupo, dependiendo de la pormenorización normativa recogida en sus leyes de régimen local. En cuanto al régimen legal establecido por dicha legislación, se hará referencia a él en el próximo apartado, pero sirva, a modo de adelanto, la mera enumeración de los preceptos generales y más relevante que al respecto interesan, sin perjuicio de las matizaciones y extensiones que se hagan más adelante en este trabajo.

De forma concreta deben ser citados los artículos 14 , el 22 y $47^{18}$ de la Ley 7/1985, de 2 de abril, reguladora de las Bases del Régimen Local, y 27 a 30 del Real Decreto 1690/1986, de 11 de agosto, por el que se aprueba el Reglamento de Población y Demarcación Territorial de las Entidades Locales.

\section{CAMBIO DE DENOMINACIÓN DE LOS MUNICIPIOS DE LA COMUNIDAD VALENCIANA. PROCEDIMIENTO ADMINISTRATIVO}

\section{II.1. Competencias normativas}

Nuestro texto constitucional, en su artículo 148.2, determina, como posibles competencias asumibles por las Comunidades Autónomas, las

\footnotetext{
17 Iniciativas en este mismo sentido se han llevado a cabo en otras Comunidades Autónomas, como Cataluña, que por medio de la Orden del Departamento de Gobernación de 20 de diciembre de 1988, aprueba los Nombres oficiales, unidades de población y entidades municipales descentralizadas.

18 Artículos 22 y 47 recientemente modificado por la Ley 57/2003, 16 de diciembre, de medidas para la modernización del gobierno local.
} 
alteraciones de los términos municipales comprendidos en su territorio y, en general, las funciones que correspondan a la Administración del Estado sobre las Corporaciones locales y cuya transferencia autorice la legislación sobre Régimen Local.

Visto el tenor del precepto constitucional, es fácil comprender que, por medio del mismo, se permitía el ejercicio de competencias sobre régimen local por parte de los entonces entes preautonómicos, con la única exigencia, lógica por otra parte, de que se produjese la correspondiente transferencia de competencias.

Por cuanto se refiere al caso valenciano, fue el Real Decreto 695/1979 ${ }^{19}$ de 13 de febrero, sobre transferencia de competencias de la Administración del Estado al Consejo del País Valenciano ${ }^{20}$ en materia de Interior, el que, en el momento preautonómico, procedió a la transferencia, entre otras, de las competencias en materia de cambios de denominación municipal.

El artículo primero de dicho Real Decreto comenzaba diciendo que se transferían al Consejo del País Valenciano una serie de competencias de la Administración del Estado en materia de organización, régimen jurídico, bienes y servicios de las Corporaciones Locales. El apartado segundo de este primer artículo, titulado «organización», recogía en su numeral tercero la transferencia de la competencia para «la alteración de los nombres y capitalidad de los municipios».

El segundo artículo de la norma reglamentaria determinaba que, en una serie de supuestos, entre los que se incluía el de cambio de denominación de municipios, la resolución de los expedientes correspondía al Consejo del País Valenciano, previo informe de la Diputación Provincial respectiva.

Por su parte, el artículo tercero señalaba que serían de aplicación a las transferencias efectuadas lo "prevenido» en el capítulo II, artículos 42 a 46, con excepción de los números 2 y 3 del artículo 44, del Real Decreto

\footnotetext{
${ }^{19}$ Existieron Reales Decretos de contenido similar, que suponían la trasferencia de competencias en materia, entre otras, de cambio de denominación municipal a favor de distintos entes preautonómicos. Al respecto puede mencionarse el artículo 2.3 del Real Decreto 698/1979, de 13 de febrero, que lo hacía en favor de Andalucía, el 2.3 del Real Decreto 2115/1978, de 26 de julio, a favor de la Generalitat Catalana, o el artículo 2.3 del real decreto 2488/1978, de 25 de agosto, a favor del ente vasco. Como puede apreciarse por la coincidencia de los artículos, nos encontramos ante una operación de transferencia cuasi uniforme de competencias a distintos entes preautonómicos.

${ }^{20}$ Dicha calificación se da al órgano de gobierno preautonómico valenciano por medio del Real Decreto-Ley 10/1978, por el cual se instituye.
} 
299/1979, de 26 de enero, sobre transferencia de competencias de la Administración del Estado al Consejo del País Valenciano, en materia de agricultura, urbanismo, turismo, ferias interiores y transportes. En tales artículos se regulaba el régimen general de ejercicio de las competencias transferidas, refiriéndose a extremos tales como el sistema de recursos, la posibilidad de desarrollo normativo de las mismas, el sistema de responsabilidad patrimonial del ente preautonómico, o su sometimiento a la legislación general sobre Administraciones públicas.

Señalaba asimismo la Disposición Final Segunda de la norma analizada que, las competencias a que se refería la misma, empezarían a ejercerse por el ente preautonómico a partir del 2 de julio de 1979, en cuya fecha habían de dejar de intervenir los órganos estatales anteriormente competentes, salvo para remitir al Consejo del País Valenciano los documentos referentes a las funciones y servicios traspasados. Estas últimas indicaciones estaban en relación directa con la Disposición Transitoria Primera, donde se decía que los expedientes iniciados antes del 2 de julio de 1979, que versasen sobre materias objeto de transferencia por el Real Decreto de referencia, se concluirán en todos sus incidentes, incluso recursos, por los órganos competentes, si estos fueran los Servicios Centrales de la Administración del Estado. Esta última salvedad es la que sirve para explicar porque, tras la entrada en vigor del Real Decreto 695/1979 (2 de julio 1979), todavía algunos cambios de denominación de municipios valencianos, como el de Alcudia de Carlet por l'Alcúdia (Valencia), aprobado finalmente en 1980, fueron realizados mediante Acuerdo del Consejo de Ministros y no por Decreto del Consell.

Como último punto a comentar del Real Decreto 695/1979, sería interesante referirnos a la Disposición Transitoria Tercera, la cual establecía que el Consejo del País Valenciano organizaría los servicios precisos y distribuiría, entre los órganos correspondientes, las competencias que se le transferían. Y ello tuvo lugar por medio del Decreto del Consell, de 2 de agosto de 1979, en el cual se hacía la distribución de las competencias estatales recibidas.

Este Decreto de 2 de agosto de 1979, en su primer artículo, establecía que correspondía a la Consellería de Interior la gestión de las competencias que se contenían en el Real Decreto 695/1979, asignándosele, igualmente, la exclusividad en las funciones administrativas derivadas de dichas competencias. Pero ante esta exclusividad en la tramitación de los expedientes administrativos, se establecía un doble sistema en lo referente a su resolución. Este doble sistema consistía en que determinados expedientes debían ser resueltos por el Conseller de Interior, y otros, debían 
serlo por el Pleno del Consell, todo ello sin perjuicio de la posibilidad reconocida por el propio texto de proceder a delegaciones en órganos directamente inferiores. Fue el artículo 5.2.3, el que determinó que los expedientes relativos a la alteración de los nombres y capitalidad de los municipios fuesen resueltos por el Pleno del Consell.

Hemos visto como, por medio de normas reglamentarias, se procedió, de manera temprana, al traspaso de competencias en materia de cambio de denominación de municipios a favor del ente preautonómico valenciano, y como éste procedió a su asignación a la Consellería de Interior, por cuanto se refería a la instrucción, dejando la resolución al Pleno del Consell. Pero el afianzamiento competencial definitivo sobre la materia se realizó por medio de la inclusión expresa de dicha competencia entre las propias de la Comunidad Valenciana en su Estatuto de Autonomía. El artículo 31.8 de la norma básica valenciana, dice textualmente que, «la Generalidad Valenciana tiene competencia exclusiva sobre las siguientes materias: (...) alteraciones de los términos municipales y denominación oficial de los municipios y topónimos». Con esta recepción estatutaria de la competencia se determinó de modo invariable la voluntad de asunción de la misma por los órganos políticos y de gobierno valenciano, evidenciándose la importancia que para los mismos suponía la concreta labor de renombramiento municipal.

La atribución exclusiva de la competencia sobre alteración de los nombres de los municipios hecha por el Estatuto de Autonomía a favor de la Administración autonómica valenciana, debería ser la última estación del viaje en busca de la titularidad competencial al respecto. Pero hemos querido dar un paso más y reflejar la recepción que de ello se hizo en la Ley 4/1983, de 23 de noviembre, de uso y enseñanza del valenciano, pues consideramos que ello es nexo de unión entre la cuestión competencial y el régimen legal vigente.

El artículo 15 de la Ley 4/1983, hace una serie de menciones relativas tanto a atribuciones competenciales como a efectos legales derivados de la denominación municipal oficial. Las referencias en el seno de una ley que regula el régimen jurídico de la lengua propia, no hace más que respaldar la idea de que política lingüística y cambio de denominación municipal se encuentran, en regiones con lengua autóctona, estrechamente unidos. De forma sucinta, y por cuanto se refiere a la competencia sobre la materia, puede señalarse que, según la Ley 4/1983, es al Consell de la Generalitat Valenciana a quien corresponde, conforme a los procedimientos legalmente establecidos, determinar, entre otros, los nombres oficiales de los municipios (artículo 15.1). 
La configuración de competencia exclusiva sobre la materia a favor de la Comunidad Valenciana, y, en concreto, del Pleno de su órgano ejecutivo, es por tanto clara, si bien, hasta no hace demasiado, había quien no lo comprendía así, debiendo recordárselo el propio Tribunal Supremo por medio de su sentencia de 21 de febrero de 2000. El asunto que llegó al Alto Tribunal versaba sobre el cambio de denominación del municipio castellonense de La Vall d'Uixó, anteriormente conocido por el nombre oficial de Vall de Uxó, el cual fue modificado por Decreto del Consell $6 / 1989$, de 30 de enero.

Un grupo de concejales del citado Ayuntamiento, impugnaron el Decreto que aprobaba el cambio de denominación, alegando que la modificación que sufría el nombre del municipio no era un simple cambio lingüístico, sino un cambio real de nombre -como si la adaptación a la lengua propia fuese un cambio «irreal»-, y que por tanto no eran de aplicación las normas autonómicas sobre la materia, sino la legislación estatal. Ante tan poco tino jurídico, y lingüístico, la Sala procedió a desestimar dichos postulados, y lo hizo en dos sentidos. El primero fue afirmar que la variación en el nombre del municipio era, evidentemente, una adaptación a la lengua de la Comunidad, lo cual puede apreciarse fácilmente si se observa el nombre inicial y el modificado. El segundo fue que, aún no habiendo sido ese el caso, es decir, que no se tratase de una «simple» adaptación lingüística, las normas autonómicas que regulan el procedimiento tienen preferencia en su aplicación sobre las estatales, "sólo aplicables con carácter subsidiario». Y ello es así porque la competencia sobre la alteración de términos municipales y denominación de municipios, fue atribuida en exclusiva a la Comunidad Valenciana por su Estatuto de Autonomía. Por ello, acaba diciendo la sentencia en su fundamento tercero, «tanto en el orden sustantivo como en el procedimiento, deben ser aplicadas las normas autonómicas y no las generales».

Dos preceptos deben ser mencionados para dar por conclusas las referencias a la competencia sobre el cambio de denominación municipal. Se trata de los artículos 26.1 y 28 del Real Decreto 1690/1986, de 11 de julio, por el que se aprueba el reglamento de población y demarcación de las Entidades Locales, en los cuales se hace una atribución expresa a favor del «Consejo de Gobierno de la Comunidad Autónoma», en materia de aprobación de los expedientes de cambio de nombre y capitalidad de sus municipios. Tenemos ante nosotros una norma estatal que juega a modo de cláusula de cierre, y que permite afirmar, ya sin reservas de ningún tipo, que los órganos competentes para decidir sobre los expedientes de cambio de denominación de los municipios, no son otros que los ejecutivos autonómicos respectivos, siendo la cuestión de la normativa aplicable 
algo a resolver caso a caso, y que depende en gran medida de la voluntad política puesta en ello. Lo que es indudable es que, en el caso de la Comunidad Valenciana, la atribución competencial y el régimen legal aplicable corresponden en exclusiva a los órganos de gobierno de la misma.

\section{II.2. Régimen jurídico aplicable al cambio de denominación de los municipios valencianos}

Una vez aclarada la cuestión del título competencial que faculta al órgano de gobierno valenciano para establecer las normas que deben regir las peticiones relativas al cambio de denominación formuladas por los municipios incluidos dentro de sus límites geográficos ${ }^{21}$, así como las relativas a la tramitación y resolución de dichos procedimientos, es ahora tiempo de pasar a conocer el régimen concreto que disciplina el procedimiento administrativo que ha de seguirse para que pueda darse el cambio en la forma oficial en que se conoce una localidad.

\section{Antecedentes}

Con la atribución de competencias que acaba de ser comentada, se sentaron las bases del procedimiento sobre cambio de denominación de municipios en el seno de la Comunidad Valenciana, al menos por cuanto se refería a los órganos gubernativos implicados y a sus funciones. Pero estos textos, apenas establecieron exigencias referidas al procedimiento administrativo de instrucción del expediente.

Fue por ello, por lo que en un primer momento, se articuló un sistema mixto para el conocimiento de estos asuntos, en el cual confluían prescripciones de origen autonómico, como las que determinaban los órganos competentes ${ }^{22}$ para la instrucción, Consellería de Interior, y la resolución, Pleno del Consell, con otras de procedencia estatal, como las que determinaban el informe previo de la Diputación Provincial correspondiente ${ }^{23}$, y las contenidas en la normativa sobre régimen local vigente en aquel momento, es decir, la Ley de Régimen Local de 24 de Junio de 1955, el

\footnotetext{
21 El artículo tercero del estatuto de Autonomía Valenciano establece que, el territorio de la Comunidad Autónoma comprende el de los municipios integrados en las provincias de Alicante, Castellón y Valencia.

22 Artículos 4 y 5 del decreto del Consell de 2 de agosto de 1979.

23 Determinado por el artículo tercero del Real Decreto 695/1979.
} 
Real Decreto-Ley 3/1981, de 16 de enero, que aprobaba medidas sobre el régimen jurídico de las corporaciones locales, y el anterior Reglamento de Población y Demarcación Territorial de las Entidades Locales, aprobado por Decreto de 17 de mayo de 1952, normas hoy derogadas tanto por la Ley $7 / 1985$, de 2 de abril, reguladora de las bases del régimen local (en adelante LRBRL), como por el Real Decreto 1690/1986, de 11 de julio, por el que se aprueba el reglamento de población y demarcación de las Entidades Locales.

Esta situación de fuentes múltiples se mantuvo hasta 1984, momento en el que el Consell de la Generalitat Valenciana aprobó el Decreto 74/1984, de 30 de julio, por el que se regulaba el procedimiento para la alteración del nombre de los municipios.

La exposición de motivos de esta norma la ponía en relación con una serie de preceptos que no hacían más que evidenciar su relación con la política lingüística de la Comunidad, pues se mencionaban los artículo 3.2 de la Constitución ${ }^{24}$, el 7 del Estatuto de Autonomía ${ }^{25}$ y el 34 de la Ley $4 / 1983$ de enseñanza y uso del valenciano ${ }^{26}$.

Merece especial interés una afirmación que se hace en la parte final de la exposición de motivos, y que nos da una idea de la necesidad real que había de contar con un procedimiento propio y diferenciado del general establecido por la normativa estatal. Podía leerse textualmente que «considerando que el cambio de nombre oficial de los municipios por razones estrictamente lingüísticas ${ }^{27}$, o su denominación en las dos lenguas de la Comunidad, no está prevista en la legislación vigente de régimen local ${ }^{28}$, pues sólo prevé (...) cambios de nombre motivados por razones de carácter histórico o tradicional».

Más allá de las consideraciones que puedan hacerse sobre si renombrar un municipio con su denominación en lengua valenciana, es o no un cam-

\footnotetext{
${ }^{24}$ Las demás lenguas españolas serán también oficiales en las respectivas Comunidades Autónomas de acuerdo con sus Estatutos.

${ }^{25}$ Los dos idiomas oficiales de la Comunidad Autónoma son el valenciano y el castellano.

${ }^{26}$ El Gobierno valenciano asumirá la dirección técnica y la coordinación del proceso de uso y enseñanza del valenciano asesorando al respecto a todas las administraciones públicas y particulares y adoptando cuantas medidas contribuyan al fomento de su uso y extensión.

${ }^{27}$ Quizás en un principio, tampoco el legislador autonómico tenía muy clara que la competencia sobre la materia le correspondía en exclusiva, independientemente del tipo de cambio que se propusiese.

${ }^{28}$ Se refería al artículo 38 del Reglamento de población y demarcación territorial entonces vigente, Decreto de 17 de mayo de 1952.
} 
bio de carácter histórico o tradicional, lo que no ofrecía dudas al ejecutivo valenciano era que, realmente, no existían previsiones normativas adecuadas en la legislación de régimen local estatal para hacer frente al nuevo fenómeno que se estaba planteando, por lo que se hacía necesario dotarse de una regulación clara y ajustada a las necesidades concretas del procedimiento.

Se trató de un reglamento corto, el cual no constaba más que de seis artículos en los que, sin embargo, se trazaba un más que aceptable procedimiento, donde los informes debían ser emitidos por los órganos competentes en política lingüística de la Comunidad, y donde se marcaban claramente las fases municipal y gubernativa autonómica del procedimiento.

La vigencia del Decreto 74/1984 fue de ocho años, a lo largo de los cuales les fue aplicado a cerca de medio centenar de expedientes, siendo finalmente derogado por el Decreto 58/1992, de 13 de abril, actualmente en vigor. Aunque más que una derogación propiamente dicha, la entrada en vigor del decreto 58/1992 fue, como acertadamente se señala en su exposición de motivos, una adecuación del procedimiento regulado en 1984 a las nuevas circunstancias. Dichas nuevas circunstancias requerían, principalmente, adaptar la norma de 1984 a la regulación sobre régimen local vigente, la cual había cambiado de forma relevante con la aprobación de la LRBRL, que derogó las anteriores normas sobre régimen local, a las que se hacía referencia en el Decreto 74/1984. También se buscaba incluir en el texto referencias al Consejo Valenciano de Cultura, creado por Ley 12/1985, de 30 de octubre, y a la Dirección General de Política Lingüística, creada por Ley 7/1990, de 28 de diciembre, de Presupuestos de la Generalitat Valenciana. Por último, se buscaba ampliar las garantías del procedimiento introduciendo un trámite de audiencia para aquellos casos en los que hubiese discrepancias entre el órgano competente en materia de política lingüística y la propuesta presentada por el ayuntamiento correspondiente.

Una vez introducida la norma que actualmente regula el procedimiento de cambio de denominación de los municipios en la Comunidad Valenciana, es momento de pasar a analizar las distintas fases y exigencias legales que envuelven al mismo, para comprender en toda su extensión el fenómeno a estudio.

\section{Régimen Vigente}

En este apartado, tras los comentarios que acaban de hacerse respecto a su génesis y justificación, pasamos a realizar un recorrido por el Decre- 
to 58/1992, de 13 de abril, del Gobierno Valenciano, en el que se regula el procedimiento para la alteración del nombre de los municipios. Al respecto, la primera referencia que debemos hacer se relaciona con los distintos apartados del artículo primero del Decreto, en el cual se hacen una serie de indicaciones previas que han de ser tenidas en cuenta a la hora de iniciar un expediente de cambio de denominación municipal. Este artículo inicial tiene cuatro apartados, de los cuales merece ser comentado lo siguiente:

Se hace hincapié, en el primer apartado, en que la nueva denominación del municipio debe adecuarse a su tradición histórica y lingüística. Vemos aquí como pretende subsanarse de forma expresa la ya comentada carencia que se atribuía a la norma estatal, en el sentido de la insuficiencia de la vertiente histórica a la hora de determinar la nueva denominación de un municipio, pues dicha vertiente se considera necesario que cuente, indefectiblemente, con el concurso de la lingüística, dado que tan importante es conocer el nombre clásico de una población, como ser capaz de escribirlo correctamente.

El segundo apartado del artículo primero, señala que los municipios no podrán usar nombres que no hayan sido autorizados con arreglo a los trámites reglamentarios que se prevén en el propio Decreto. Ello ha de conectarse con el artículo 15.1 de la Ley 4/1983 de enseñanza y uso del valenciano, el cual afirma que corresponde al Consell de la Generalidad Valenciana, acorde con los procedimientos legales establecidos, determinar los nombres oficiales de los municipios ${ }^{29}$.

El tercer apartado explicita que la denominación de los municipios podrá ser en castellano, en valenciano o en ambas lenguas, debiéndose utilizar, en este último caso, ambas como forma oficial de denominación. Al respecto, el 15.3 de la Ley 4/1983 establece que los municipios que tuvieran denominación en las dos lenguas de la comunidad, harán figurar su nombre en $\operatorname{ambas}^{30}$.

Por último, el cuarto numeral se estipula que no serán autorizadas alteraciones de nombres municipales, cuando el que se proponga sea idéntico a otro existente, o pueda producir confusiones en la identificación de las

\footnotetext{
${ }^{29}$ En el mismo sentido el artículo 30.3 del Real Decreto 1690/1986, de 11 de julio, por el que se aprueba el Reglamento de Población y Demarcación de las Entidades Locales. Norma estatal de aplicación supletoria.

${ }^{30}$ En el mismo sentido se manifiesta el artículo 14.2 de la Ley 7/1985, reguladora de las Bases del Régimen Local, cuya aplicación, como ya ha sido apuntado, es supletoria. También lo hace el artículo 30.2 del Real Decreto 1690/1986.
} 
Administraciones ${ }^{31}$. Sobre un caso de denegación de cambio de nombre por similitud con la denominación de otro municipio, trató el Decreto del Consell 196/2002, de 3 de diciembre, por el que se denegó el cambio de denominación del municipio del Muro de Alcoy, por el de Muro, al existir ya, en Illes Balears, un municipio con dicho nombre. El caso de Muro de Alcoy ha sido el único en el que el Gobierno valenciano no ha accedido a proceder al cambio solicitado. De hecho, desde la Consellería de Justicia y Administraciones Públicas, se presentaron al Consistorio alicantino algunas variantes posibles, las cuales, finalmente, no fueron aceptadas por éste.

Tras estos breves comentarios referidos a cuestiones de índole general que afectan al procedimiento, vamos a comenzar con el mismo.

El procedimiento tiene dos fases claramente definidas, una primera fase, que tiene lugar en el propio Ayuntamiento interesado, que hemos denominado municipal, y una segunda que se desarrolla en el seno de la Administración Autonómica, a la que hemos venido a llamar gubernativa. A la primera de ellas se dedican los artículos segundo y tercero, correspondiendo el resto, del cuarto al octavo, a la segunda.

\section{Fase Municipal}

\section{Iniciación}

El expediente de alteración del nombre de los municipios se iniciará mediante acuerdo del Ayuntamiento en pleno $^{32}$, requiriéndose por la norma el quórum que establece el artículo 47.2.d) de la LRBRL. Vemos como se hace aquí una referencia directa a la normativa estatal sobre régimen local, sin ser ello necesario, pues hubiese bastado con indicar la mayoría exigida. Esta mención expresa de la norma estatal parece traslucir una intención de entrelazar, de algún modo, ambos textos, buscando la confirmación o el respaldo que ello pudiera suponer. En otros casos similares, como el vasco (artículo 2 del Decreto 271/1983, de 12 de diciembre) o el catalán (artículo 3 de la Ley 12/1982, de 8 de octubre), no se ha considerado necesaria la referencia a una norma que, aún teniendo carácter supletorio, nada aportaba, quedando por ello en el aire la duda sobre el motivo real de dicha alusión.

\footnotetext{
31 En el mismo sentido el artículo 30.4 del Real Decreto 1690/1986.

32 En el mismo sentido se manifiesta el artículo 22.2.b) de la Ley 7/1985.
} 
La mayoría concreta que se exige viene determinada en el artículo 47.2.d) de la LRBRL, cuya redacción ha sido varias veces modificado desde que la ley estatal de régimen local fuese sancionada. En 1992 el artículo 47.2.d) de la LRBRL exigía el voto favorable de las dos terceras partes del número de hecho $\mathrm{y}$, en todo caso, de la mayoría absoluta del número legal de miembros de la Corporación ${ }^{33}$, para adoptar acuerdos relativos a la alteración del nombre y de la capitalidad de los municipios. En la redacción actual del artículo, dada por la Ley 57/2003, de 16 de diciembre, de medidas para la modernización del gobierno local, se pide directamente el voto favorable de la mayoría absoluta del número legal de miembros de la Corporación, eliminando, por tanto, la referencia a que el acuerdo se adoptase por las dos terceras partes de los miembros de hecho. Especial atención merece en este punto, al apartado tercero que introduce la Ley 57/2003, a este artículo 47. En este nuevo apartado, se remite al artículo 123 de la propia LRBRL, a los efectos de determinación de las mayorías para la adopción de acuerdos en los supuestos de municipios considerados de gran población ${ }^{34}$. Para tales municipios, en el caso de pretender el cambio de denominación del municipios (art.123.1.e)), se requiere, el voto favorable de la mayoría absoluta del número legal de los miembros del Pleno. Como puede observarse se da una identidad de mayorías independientemente del tipo de municipio del que se trate.

\section{Informes}

El expediente requiere de una serie de informes mediante los cuales debe razonarse, de manera justificada, el cambio que se propone. Dichos informes, a parte del que debe emitir la secretaría del Ayuntamiento, se encomiendan a particulares o entidades con suficiente «autoridad» sobre el tema.

En los diversos expedientes que finalmente han llegado ante la administración Autonómica Valenciana, no sólo durante la vigencia del Decre-

\footnotetext{
${ }^{33}$ Esta misma mayoría es la que sigue exigiendo el artículo 26.2 del Real Decreto 1690/1986, el cual no ha sido modificado, y dada esta falta de modificación el contenido del Real Decreto determina una mayoría distinta a la establecida por la LRBRL tras la reforma introducida por la Ley 57/2003, de 16 de diciembre, de medidas para la modernización del gobierno local.

${ }^{34}$ El artículo 121 de la Ley 7/1985 los define: municipios cuya población supere los 250.000 habitantes, los municipios capitales de provincia con población superior a los 175.000 habitantes, los municipios que sean capitales de provincia, capitales autonómicas o sedes de las instituciones autonómicas, asimismo, a los municipios cuya población supere los 75.000 habitantes, que presenten circunstancias económicas, sociales, históricas o culturales especiales.
} 
to 58/1992, sino también con anterioridad, los informes remitidos por los Ayuntamientos han sido de lo más variado. Así, se han presentado informes de los denominados cronistas de la localidad. También se han presentado informes por parte de «peritos», tales como profesores de Universidad, de educación secundaria, Licenciados en Arte, en Historia, o en Filología Clásica. Un tercer grupo de informes han sido emitidos por agrupaciones de todo tipo relacionadas con la lengua y la historia valenciana, así lo hizo la Secció d'Historia i Geografía de lo Rat Penat, la Asociació Amics de Vinaròs o la Sociedad Castellonense de Cultura. Igualmente, gran parte de expedientes unen informes de distintos Departamentos Universitarios, principalmente del Instituto de Filología Valenciana de la Universidad de Valencia, y del Departamento de Lingüística Valenciana de la Facultad de Filosofía, de la misma Universidad. Pero, sin duda alguna, el informe más sorprendente que se ha aportado por parte de un municipio fue el presentado por Xàtiva cuando reclamó esta denominación, en detrimento de la castellanizada de Játiva. En este caso, que fue finalmente resuelto de manera positiva por Decreto del Consell de 7 de enero de 1980, se aportó, junto al informe de un perito experto en lenguas clásicas, fotocopia del Decreto de las Cortes Generales, fechado en Cádiz en octubre de 1811, por el que se ordenaba, ya entonces, la restitución a la ciudad de su «antiguo» nombre de «Xativa» ${ }^{35}$.

Para concluir estas referencias a los informes adjuntos a los expedientes presentados por los municipios, podría hacerse referencia a los emitidos por las Diputaciones Provinciales dentro de cuyos límites se encuentra el municipio que pretende alterar su denominación. En el caso valenciano, estos informes dejaron de solicitarse con la entrada en vigor del Decreto 74/1984, de 30 de julio, pero con anterioridad, la normativa vigente los exigía. Aún hoy la normativa estatal los pide ex artículo 26.1 del real decreto 1690/1986.

\section{Exposición al público}

El Decreto 58/1992 determina un plazo de exposición pública de un mes, el cual se da a conocer e inicia por medio de anuncios en el Boletín Oficial de la Provincia y en el tablón de edictos del Ayuntamiento, a fin de que los interesados puedan formular alegaciones ${ }^{36}$.

\footnotetext{
35 Recuérdese el ejemplo puesto en la primera parte del trabajo.

36 En el mismo sentido la norma estatal por medio del artículo 27.2.a) del Real Decreto 1690/1986. Este artículo es de aplicación a los cambios de denominación de municipios por prescripción del artículo 29 del propio texto.
} 
Por cuanto respecta a este período ha de estarse al contenido del artículo 86 de la LRJ-PAC ${ }^{37}$, titulado «información pública». En dicho precepto, aparte de reconocerse la posibilidad a las distintas Administraciones de acordar un periodo de este tipo, se señala que el mismo se llevará a efecto por anuncios en el diario oficial correspondiente, con la finalidad de que cualquier persona, física o jurídica, pueda examinar el expediente o la parte del mismo que se acuerde. En el anuncio debe señalarse el lugar concreto de exhibición y el plazo para presentar alegaciones, el cual no puede, en ningún caso, ser inferior a veinte días. Indica también el precepto que, la incomparecencia a este trámite no supone la pérdida de la condición inicial de interesado, pero eso sí, la presentación de alegaciones tampoco la otorga, dando, a lo sumo, derecho a obtener una respuesta razonada, que podrá ser común para todas aquellas alegaciones que planteen cuestiones sustancialmente iguales. En última instancia, se reconoce la posibilidad de establecer otros medios y cauces de participación de los ciudadanos, bien directamente o bien por medio de organizaciones o asociaciones legalmente reconocidas.

Deben ser tenidas en cuenta las prescripciones del Capítulo IV, Título $\mathrm{V}$, de la LRBRL, titulado Información y Participación Ciudadana, donde se impone la obligación a los poderes públicos locales de facilitar tanto una como otra, habilitando para ello todo tipo de medios, incluso telemáticos. Debiendo favorecer igualmente la articulación de los intereses ciudadanos a través de asociaciones y ofreciendo de forma clara y precisa toda la información disponible sobre cualquier actividad desarrollada por el Consistorio.

En cuanto a la mención que el artículo tercero del Decreto 58/1992 hace a los interesados, debe dejarse claro que no consideramos que el uso del término hecho por la norma sea adecuado. Esto se dice por el hecho de que, como bien señala el artículo 86 de la Ley 30/1992, en el periodo de exposición pública, "cualquier persona, física o jurídica» puede presentar alegaciones, reforzando este postulado la mención que se hace al hecho de que, ni la presentación de las mismas otorga la condición de interesados, ni la no presentación afecta al interesado en su posición como tal. Es indudable que este período tiene como finalidad poner en conocimiento de posibles interesados la existencia del expediente, cuya resolución pudiera afectarles de alguna forma. Pero se ha utilizado igualmente como medio para conocer la opinión del público general e indeterminado que, aún no teniendo un interés directo en el procedimiento, de alguna

37 De aplicación al caso que nos ocupa por su concepto de normativa básica conforme al artículo 149.1.18 CE. 
forma no es indiferente a la cuestión sobre la que se ha de resolverse ${ }^{38}$. En este sentido se ha afirmado que la información pública constituye un trámite de alegaciones capaz de aportar al expediente puntos de vista inicialmente desconocidos ${ }^{39}$. Una vez señalada la incorrección del término utilizado, no puede más que instarse su eliminación, haciéndose simplemente referencia a un período de información pública durante el cual, y conforme a la legislación vigente, cualquiera pueda alegar.

De todos modos, debe deslindarse la posición de los terceros que puedan tener «algo que decir», de aquellos otros que hemos de considerar realmente interesados, a los cuales les asisten todos los derechos que, como tales, les reconoce el ordenamiento jurídico, entre ellos, y de forma básica, el de alegar en cualquier momento del procedimiento ${ }^{40}$ y el de plantear los recursos oportunos ${ }^{41}$. Acudiremos en este punto al artículo 31 de la propia LRJ-PAC, donde, para supuestos como el de cambio de denominación municipal que es un procedimiento que se inicia de oficio, se nos dice que son interesados aquellos que, sin haber iniciado el procedimiento, tengan derechos que puedan resultar afectados por la decisión que en el mismo se adopte, y aquellos otros cuyos intereses legítimos, individuales o colectivos, puedan resultar afectados por la resolución y se personen en el procedimiento en tanto no haya recaído resolución definitiva. Todo ello sin olvidar a las asociaciones y organizaciones representativas de intereses económicos en los términos legalmente establecidos.

En buena lógica, pensamos que, al menos en principio, los verdaderos interesados no son otros que los vecinos del municipio sobre cuya denominación se está tratando, bien actúen de manera individual, bien agrupados o asociados. No así los concejales, pues ellos tienen su foro y momento para «alegar» en el Pleno que debe votar la propuesta, cosa distinta es que puedan impugnar los acuerdos adoptados por el pleno en los cuales ellos votaron en contra (artículo.63.1.b LRBRL). Por cuanto se refiere a hipotéticos terceros, como municipios con denominaciones similares a las propuestas o asociaciones de corte político, histórico o lingüístico de ámbito distinto al del municipio, sería el plazo de información pública el

\footnotetext{
38 J. GonzÁlez PÉrez y F. GonzÁlez NAVArro, «Comentarios a la Ley de Régimen Jurídico de las Administraciones Públicas y del Procedimiento Administrativo Común. Ley 30/1992. Tomo II». Ed Civitas. Madrid 2004. p. 2141.

39 E. García de Enterría y T.R. Fernández, «Curso de Derecho Administrativo. Tomo II». Ed Civitas. Madrid 2002.

40 Art. 35.e) LRJ-PAC.

41 Art. 107 LRJ-PAC.
} 
momento procesal oportuno para presentar sus propuestas y reivindicar sus alternativas, quejas o denuncias, ello, claro está, siempre que los escasos efectos reales de la publicidad edictal lo permitiese.

\section{Resolución de las alegaciones}

Existe obligación de dar solución y notificar, bien de forma individual, bien colectiva, en todos los casos en que se presenten alegaciones ${ }^{42}$. Como se ha indicado, esta obligación de la Administración no otorga, en ningún caso, la condición de interesado, lo que no supone, sin embargo, que la respuesta no sea dada. Además, el Decreto 58/1992 exige el mismo quórum para resolver estas alegaciones que el establecido para adoptar el acuerdo de inicio del expediente. Esta necesidad de que el quórum sea el mismo es lógica, por cuanto las alegaciones presentadas pueden suponer desde la aportación de variantes realmente viables, hasta razones y motivos que hagan parecer conveniente no realizar cambio alguno. Como se verá más adelante, y siguiendo esta la misma lógica, en un momento posterior del procedimiento, si la Generalitat plantea alternativas al nombre propuesto, por no estar de acuerdo con el presentado por el Ayuntamiento, la mayoría exigida para aceptar dicha alternativa por parte del Pleno municipal, será exactamente la misma que se pide para iniciar el expediente y para resolver las alegaciones.

Cabe el caso, bastante corriente en este tipo de expedientes, de que no se presenten alegaciones de ningún tipo. En tales supuestos bastará con unir al expediente certificación acreditativa de dicho extremo, la cual debe ser expedida por el secretario de la Corporación, sin que se necesario un nuevo acuerdo del Pleno.

\section{Remisión del expediente a la Administración Autonómica}

Una vez completada toda la tramitación del expediente, y encontrándose adjuntas las certificaciones e informes correspondientes, todo ello debe remitirse a la Consellería de Administración Pública, dando así por concluida la fase en sede municipal e iniciándose la gubernativa.

En este punto, una vez concluida la fase municipal, y cuando la posición del Consistorio ya ha quedado consensuada por los dirigentes políti-

\footnotetext{
42 Esta obligación de resolver las alegaciones presentadas, se establece igualmente en el artículo 27.2.b) del Real Decreto 1690/1986, pero sin hacerse indicaciones de ningún tipo relativas a mayorías cualificadas.
} 
cos locales, es el momento que entendemos sería idóneo para dar entrada a la opinión popular. El cambio de denominación del lugar en el que se vive, con cuyo gentilicio nos identificamos y por el que somos conocidos, es un asunto de suficiente relevancia como para que la ciudadanía quede al margen de la decisión al respecto. Medidas político-administrativas como la de solicitar la modificación del nombre de la localidad no puede por menos que depender de la voluntad popular especialmente manifestada al respecto, sin que el apoderamiento general que da la representación política obtenida en las urnas cada cuatro años pueda entenderse suficiente a los efectos de una decisión de tal calado. Por este motivo entendemos que debe aplicarse el artículo 71 LRBRL a este tipo de supuestos, pues el cambio de denominación del municipio es, sin duda, un asunto local de especial relevancia para los intereses de los vecinos, susceptible, por tanto, de consulta popular. Cabría igualmente la posibilidad de que esta consulta se llevase a cabo una vez resuelto favorablemente el expediente por la Administración Autonómica y antes de publicar el correspondiente Decreto.

\section{Fase Gubernativa}

Los trámites que deben seguirse en la fase que hemos denominado como gubernativa, son lo siguientes.

\section{Inicio del expediente autonómico}

Recibido el expediente presentado por el Ayuntamiento, y vistos los informes justificativos que avalan la petición de alteración del nombre del municipio, la Administración actuante procederá al inicio de «su» expediente, con la solicitud de los informes que correspondan y el estudio en profundidad de la documentación aportada.

Es importante referirnos, siquiera brevemente, a la Consellería que tiene atribuidas las competencias sobre la materia. Pues aunque el Decreto 58/1992 habla de la Consellería de Administración Pública, debe tenerse en cuenta que el texto cuenta ya con más de una década de vigencia, a lo largo de la cual se han producido cambios en la estructura orgánica de la Administración autonómica valenciana, como los que también han tenido lugar en relación a los órganos de informe, sobre los que a continuación se tratará.

Las competencias en la instrucción de este tipo de procedimientos han variado a lo largo del tiempo. En un principio, cuando fueron transferidas 
las competencias sobre la materia, el órgano encargado era la Consellería de Interior, posteriormente han ido modificándose las denominaciones de esta Consellería aunque, básicamente ha conservado las mismas funciones, estrechamente vinculadas, como no podía ser de otro modo, con las competencias de organización administrativa dentro de la Comunidad Valenciana y de interior. En el Decreto que anteriormente regulaba el procedimiento, el 74/1984, las competencias se conferían a la Consellería de Gobernación, otorgándose en el vigente, a la mencionada Consellería de Administración Pública.

Para conocer que órgano cuenta en la actualidad con las atribuciones correspondientes, debe acudirse al tenor del Decreto 131/2004, de 27 de agosto, del Consell, por el que determina el número y denominación de las Consellerías en que se organiza la administración de la Generalitat Valenciana, donde aparece la denominada Consellería de Justicia y Administraciones Públicas. Por su parte, el Decreto 8/2004, de 3 de septiembre, del presidente de la Generalitat, por el que se asignan competencias a las Consellerías, en su artículo único determina que se asignan a la Consellería de Justicia y Administraciones Públicas, entre otras, las competencias relativas a interior y a Administración local. Profundizando algo más en el entramado orgánico de la Consellería actualmente encargada de instruir los expedientes sobre cambio de denominación municipal, puede apuntarse que, conforme a los artículo 25 y 29 del Decreto 133/2004, de 3 de septiembre, del Consell de la Generalitat, por el que establece la estructura orgánica de las Consellerías de la Administración de la Generalitat, y el 16 del Decreto 181/2004, de 1 de octubre, del Consell de la Generalitat, por el que se aprueba el Reglamento Orgánico y Funcional de la Consellería de Justicia y Administraciones Públicas, es la Dirección General de Administración Local, bajo la dependencia de la Secretaria Autonómica de Administraciones Públicas, quien ejerce las funciones relativas al estudio, informe y resolución de los asuntos referidos al régimen jurídico, personal, organización, bienes y servicios de las entidades locales, así como la organización territorial y su coordinación. En concreto, el artículo 16 del mencionado Decreto 181/2004, establece como una de las funciones propias de la Dirección General de Administración Local gestionar los procedimientos relativos a la alteración de la denominación de los municipios.

Por ello puede concluirse que dicha Dirección General instruye los expedientes, y que corresponde al Conseller del ramo, una vez finalizado el mismo, elevar la propuesta correspondiente al Pleno del Consell, órgano que resuelve finalmente los expedientes. 


\section{Informe del órgano competente en política lingüistica}

La actual Cosellería de Justicia y Administraciones Públicas, una vez puesto en marcha el expediente, procederá a solicitar informe del órgano competente en materia de política lingüística de la Generalitat Valenciana. Dicho informe deberá ser emitido en el plazo de un mes a partir de la fecha de solicitud del mismo.

Vemos una vez más, en este caso con claridad meridiana, como se unen de forma expresa, los conceptos de cambio de denominación municipal y de política lingüística. Así observamos como el informe emitido por el órgano con competencias en materia lingüística es el único exigido en todo el procedimiento y en virtud de su sentido, favorable o desfavorable, se continúa de una forma $\mathrm{u}$ otra $\mathrm{y}$, finalmente, se informa y propone al Pleno del Consell.

Se puede observar el cambio de motivación que se da entre este tipo de informes, y los que la normativa estatal determina. Dicho cambio gravita sobre el hecho de que, mientras el artículo 28 del Real Decreto 1690/1986, habla de informes emitidos por la Real Sociedad Geográfica o por la Real Academia de la Historia, el Decreto 58/1992, solicita el del órgano competente en política lingüística, con lo que se evidencia, vistos los órganos determinados en cada caso, cuales son las prioridades que rigen cada una de las reglamentaciones.

Es indudable que la vertiente histórica, como ya se comentó, es determinante a la hora de saber si las variaciones propuestas responden o no a la tradición que pretende recuperarse, pero, quien puede dudar que el informe lingüístico que se realiza, no se ciñe únicamente a la corrección actual del nombre propuesto, sino que profundiza en las raíces del mismo.

Sí es cierto, y así debe hacerse notar, que la norma estatal comentada, en el mismo precepto que se ha mencionado, recoge la posibilidad de que los informes sean emitidos, a parte de por las instituciones estatales comentadas, por aquellas otras «similares y especializadas» de la Comunidad Autónoma, si existieren, o la de aquellos otros organismos que se consideren oportunos. De ello se puede colegir, dado que las posibilidades se unen con la partícula adversativa «o», que los informes de la Real Sociedad Geográfica o de la Real Academia de la Historia, no son más que posibilidades, las cuales pueden sustituirse por otras, motivo por el cual, cualquier Comunidad Autónoma, aún no teniendo normativa específica, podría encargar dichos informes a sus órganos propios. Cosa distinta es si estos han de ser «similares» a los estatales o «aquellos otros» que se consideren oportunos. 
Por cuanto se refiere al órgano que hemos de considerar competente en materia de política lingüística, ocurre algo similar a lo que acontecía con la Consellería encargada de la instrucción del procedimiento, es decir, que con el paso de los años se han producido variaciones.

En un principio, y hasta la aprobación del primer decreto del Consell que regulase la materia, en 1984, se actuaba bajo el régimen mixto que fue comentado más arriba, donde los informes emitidos, tanto en fase municipal, como gubernativa, tenían un perfil heterogéneo, incluyéndose informes de historiadores, de Diputaciones Provinciales, de filólogos, y un largo etcétera, que trataban la cuestión desde distintos puntos de vista, pero sin una dirección lo suficientemente clara, al menos en cuanto a su trascendencia lingüística.

Fue el Decreto 74/1984 el que introdujo una referencia concreta al informe que debía ser emitido, en fase gubernativa, por un órgano con funciones eminentemente lingüísticas, el Gabinete de Uso y Enseñanza del Valenciano, de la Consellería de Cultura Educación y Ciencia. Una referencia debe hacerse a este informe que determinaba el artículo 4 del citado Decreto. El informe del Gabinete de Uso y Enseñanza del Valenciano, únicamente se exigía por la norma en aquellos expedientes de cambio de nombre de los municipios que «sólo supongan un cambio del actual por su denominación tradicional en valenciano». Tenemos aquí un claro ejemplo de como, en un principio, existían aún ciertos reparos, o no estaba lo suficientemente asentada, la conciencia de autonomía del territorio, produciéndose esos rasgos de timidez legislativa que fueron felizmente eliminados en la norma de 1992, en la cual se exige el informe del órgano competente en materia lingüística en todos los casos.

Lo que se acaba de decir, sin embargo, deja varias cuestiones en el aire, de las cuales trataremos las dos que nos parecen más interesantes. La primera hace referencia a los hipotéticos supuestos de cambio de denominación municipal en que, habiéndose planteado bajo el imperio del Decreto 74/1984, no supusiesen la adaptación del nombre del municipio a su forma valenciana. Dicho suceso no aconteció, pero parece evidente que, en tal caso, y ante la imprevisión de la norma autonómica al respecto, debería haberse aplicado la normativa estatal que deviene supletoria.

La segunda hace referencia al régimen actualmente vigente, el cual sólo determina el informe del órgano competente en materia de política lingüística. Fue dicho más arriba que el informe histórico era necesario, pero no suficiente, debiendo ir acompañado del lingüístico. Otro tanto puede decirse a la inversa, sobre todo en casos en que lo que se solicita es el 
cambio de denominación, de castellano a castellano, donde, lógicamente, el órgano competente en materia de política lingüística poco tiene que aportar. Es bien cierto que, de los ciento setenta y un expedientes sobre cambio de denominación municipal que ha habido en la Comunidad Valenciana, sólo uno, el que modificó el nombre de Aras de Alpuente por el de Aras de Olmos, por Decreto 135/2001, supuso un cambio de denominación de castellano a castellano, pero ¿quien puede prever los que podrían iniciarse en un futuro? Por ello parece conveniente, aunque la incidencia haya sido escasa hasta ahora, prever esta circunstancia y lograr así, con la determinación del órgano que debe informar en tales supuestos, un régimen legal completo y aplicable a todos y cada uno de los expedientes que puedan presentarse. En el caso comentado del municipio de Aras de Olmos, fue el Consejo Valenciano de Cultura el que emitió informe sobre la adecuación histórica de la denominación propuesta, sin que, como es natural, informase el órgano competente en materia lingüística. Sin embargo, en los supuestos de denominación bilingüe, únicamente se emite informe sobre la denominación en valenciano, dejando sin informe la castellana que venía utilizándose, pero, ¿quien habría de informar si lo solicitado fuese cambiar la denominación de castellano a castellano y, además, hacerla bilingüe?

Ante estos dos tipos de supuestos, es decir, cambios de castellano a castellano e informe sobre la denominación castellana en supuestos de acepción legal bilingüe, la opción por el informe del Consejo Valenciano de Cultura está suficientemente razonada, por cuanto el mismo es la institución consultiva y asesora de las instituciones públicas de la Comunidad Valenciana, en aquellas materias específicas que afecten a la cultura valenciana ${ }^{43}$, por ello entendemos que debiera ser una exigencia legal y no una simple opción discrecional, como ahora ocurre vía artículo 5.1 del Decreto 58/1992.

Por cuanto se refiere al órgano competente en materia lingüística, el Decreto actualmente vigente se refiere a dicho órgano de forma genérica, previendo, comprensiblemente, que el mismo pudiese variar a lo largo del tiempo. Pero llama la atención que, en su exposición de motivos, el Decreto diga expresamente que una de las causas de la aprobación del Decreto era adecuar el procedimiento a la nueva estructura organizativa de la Administración Autonómica, modificada, entre otros aspectos, por la creación de la Dirección General de Política Lingüística. La lectura conjunta de ambas partes del texto nos lleva a pensar que, cuando el artículo

${ }^{43}$ Artículo 3 Ley 12/1985, de 30 de octubre, del Consejo Valenciano de Cultura. 
cuarto del Decreto habla de órgano competente en materia lingüística, está refiriéndose a la citada Dirección General, por lo que no entendemos el motivo por el cual no se la menciona directamente en el articulado, o bien porque no se elimina dicha referencia de la exposición de motivos. Esta última opción es, sin duda, la más sensata, y ello es así por dos motivos, el primero es que la referencia al órgano competente en materia lingüísti$\mathrm{ca}$, sin concreciones, parece una mejor opción para hacer frente a posibles cambios de denominación o funciones; el segundo, más importante, es que dicha Dirección General de Política Lingüística ha desaparecido ya.

En la actualidad, el órgano que parece tener las competencias que desempeñaba la anterior Dirección General de Ordenación e Innovación Educativa y Política Lingüística, sustituta de la Dirección General de Política Lingüística, es la Secretaría Autonómica de Cultura y Política Lingüísti$\mathrm{ca}^{44}$. Si bien, en los últimos expedientes que se han planteado sobre cambio de denominación municipal, ha sido la Academia Valenciana de la Lengua la que ha emitido el correspondiente informe.

La posibilidad de que sea la Academia Valenciana de la Lengua la que emita informe viene respaldada directamente por su norma de creación ${ }^{45}$, la cual, en su artículo 7.1.b) y e) determina como competencias de la misma fijar, a solicitud de la Generalitat, las formas lingüísticamente correctas de la toponimia y la onomástica oficial de la Comunidad Valenciana, para su aprobación oficial, y emitir y difundir informes o dictámenes y realizar los estudios sobre la normativa y la onomástica oficial valenciana, ya sea a iniciativa propia o a requerimiento de las Instituciones Públicas de la Comunidad Valenciana. Tanto por la solvencia de los miembros de esta institución, como por la especialidad de sus funciones, la Academia Valenciana de la Lengua está llamada a ser quien informe en los cambios de denominación municipal, en los casos en que se proponga volver a la denominación tradicional valenciana. Sus dictámenes se configuran como una opinión externa al Gobierno autonómico con la suficiente calidad para fundamentar adecuadamente los informes requeridos. La cuestión de si debe ser considerado como órgano competente en política lingüística tiene una fácil respuesta, y esta es negativa. Dicho órgano, como ya se ha dicho, el la Secretaria Autonómica de Cultura y Política Lingüística, por ello debe modificarse el tenor del Decreto 58/1992, en el sentido de exigir el informe no del «órgano competente en política lingüística» sino de la «Academia Valenciana de la Lengua».

44 Conforme al artículo 42 del Decreto 133/2004, de 3 de septiembre.

45 Ley 7/1998, de 16 de septiembre, de Creación de la Academia Valenciana de la Lengua. 
Esta participación de órganos externos no es novedosa en el derecho autonómico comparado, de hecho existen autonomías que han ido más allá y han creado instituciones especializadas, tal es el caso gallego ${ }^{46}$, catalán ${ }^{47}$ y asturiano ${ }^{48}$, donde se han creado las denominadas comisiones o juntas asesoras de toponimia, cuya labor, como se desprende de su denominación, consiste en el «asesoramiento, consulta y propuesta en materia de fijación oficial de los topónimos» ${ }^{49}$. Estos organismos, no sólo ejercen sus funciones en materia de denominación municipal, sino que informan y actúan en otros ámbitos, como el de los accidentes geográficos o el las entidades inframunicipales. No consideramos necesario que una institución de este calado se crease en la Comunidad Valenciana, por cuanto la Academia Valenciana de la Lengua y el Consejo Valenciano de Cultura pueden, sin duda, desarrollar las labores referidas a la toponimia valenciana, pero sí sería importante que se dotase de más cometidos a estas dos instituciones para que de forma exclusiva se encargasen de emitir los informes necesarios según el tipo de cambio de denominación solicitado.

\section{Sentido del informe del órgano competente en política lingüística}

El sentido del informe que emita el órgano competente en materia de política lingüística puede ser positivo o negativo, siendo muy diferente las consecuencias de uno y otro.

Positivo. Si el informe emitido fuese favorable a la alteración de la denominación del municipio, la Consellería de Justicia y Administraciones Públicas ${ }^{50}$ elevará propuesta al Gobierno valenciano, el cual resolverá.

Negativo. Si el informe fuera desfavorable, la Consellería de Justicia y Administraciones Públicas dará traslado del informe al Ayuntamiento interesado, planteándosele al Consistorio las alternativas que se consideren convenientes. Asimismo, se le concederá trámite de audiencia por un mes a fin de que se manifieste al respecto de las alternativas propuestas por el órgano competente en materia de política lingüística. El acuerdo al

\footnotetext{
46 Decreto 42/1979, de 21 de septiembre, de creación de la comisión toponimia gallega, modificado por Decreto 43/1984, de 23 de marzo y 174/1998, de 5 de junio.

47 Decreto 59/2001, de 23 de enero, que crea la comisión de toponimia catalana.

48 Decreto 38/2002, de 4 de abril, por el que se crea la Junta Asesora de Toponimia del Principado de Asturias.

49 Artículo único de la norma catalana.

50 El texto legal habla de la Consellería de Administración Pública.
} 
que se llegue en el Pleno municipal sobre dichas alternativas, deberá adoptarse con el mismo quórum que fue necesario para dar inicio al expediente y que se usó para dar respuesta a la alegaciones planteadas en sede municipal, es decir, la mayoría absoluta del número legal de miembros de la Corporación, o del Pleno.

Si el Ayuntamiento aceptara las sugerencias de cambio realizadas, la Consellería de Justicia y Administraciones Públicas elevará propuesta al Pleno del Consell para que resuelva.

En el supuesto de que el Consistorio no aceptase las opciones que le fueron propuestas, podrá presentar las alegaciones y documentación que considere oportuna a los efectos de defensa de su propuesta. En tal caso, la Consellería de Justicia y Administraciones Públicas dará traslado de toda la documentación y alegaciones al órgano competente en materia de política lingüística que emitió el informe, a los efectos que se manifieste sobre lo alegado por el ente municipal. El citado órgano competente en materia de política lingüística contará con quince días para emitir su informe.

Una vez finalizado este trámite, y teniendo en cuenta el nuevo informe emitido por el órgano con competencias lingüísticas, el Conseller de Justicia y Administraciones Públicas, elevará propuesta al Pleno del Consell.

\section{Resolución y notificaciones}

Todos los expedientes sobre alteración de denominación de municipios han de ser resueltos por medio de Decreto del Pleno del Consell, independientemente del sentido afirmativo o negativo del cambio. Hasta hoy únicamente ha habido un caso en el que no se dio resolución favorable, fue el caso ya mencionado del municipio de Muro de Alcoy.

El Decreto que decida sobre el cambio de denominación del municipio se notificará a la entidad local interesada y será publicado en el Diario Oficial de la Generalitat Valenciana. Además, en el supuesto de que se haya aceptado el cambio de denominación, la Consellería de Justicia y Administraciones Públicas lo comunicará a la Administración del Estado a los efectos de su anotación en el Registro de Entidades Locales ${ }^{51}$ y para su posterior publicación en el Boletín Oficial del estado.

\footnotetext{
51 Regulado por el Real Decreto 382/1986, de 10 febrero, recientemente modificado por el Real Decreto 339/2005, de 1 de abril.
} 
Con respecto al citado Registro de Entidades Locales del Estado, el artículo 14.1 de la LRBRL vincula el carácter oficial de la nueva denominación al hecho de su inscripción en este registro. De igual modo se expresa el artículo 30.1 del Real Decreto 1690/1986. Ambos textos, a su vez, establecen como requisito necesario para que alcance oficialidad el cambio de denominación municipal, el hecho de que el cambio sea publicado en el Boletín Oficial del Estado.

No cuenta la Comunidad Valenciana con un Registro de Entidades Locales de ámbito autonómico, a diferencia de lo que ocurre en otras Comunidades Autónomas como Navarra ${ }^{52}$, Galicia ${ }^{53}$, Castilla-León ${ }^{54}$, Andalucía $^{55}$ y la Rioja ${ }^{56}$, donde si existe y el cual sirve como sistema de ordenación y catalogación no sólo de los municipios de las citadas Comunidades Autónomas, sino que en el mismo también se inscriben otro tipo de organizaciones territoriales como las mancomunidades, las áreas metropolitanas o las entidades inframunicipales. Dada la funcionalidad práctica evidente de este tipo de registros, los cuales permiten la identificación clara y ordenada de todas y cada una de las distintas entidades locales que haya en la Comunidad Valenciana, así como de sus distintas formas de asociación, no puede por menos que instarse a la Administración valenciana a que actúe en consecuencia y proceda a la constitución del Registro de Entidades Locales de la Comunidad Valenciana.

\section{Sistema de Recursos}

Contra los Decretos del Consell que decidan sobre el cambio, o no, de la denominación de un municipio no cabe interponer recurso administrativo, siendo únicamente impugnables en vía Contencioso-Administrativa. Este recurso debe interponerse ante la Sala de lo Contencioso administrativo del Tribunal Superior de Justicia de la Comunidad Valenciana, en el plazo de dos meses contados desde el día siguiente al de su publicación, todo ello de conformidad con lo establecido en los artículos 107.3 y 109.c) de la Ley 30/1992 y los artículos 10, 14 y 46 de la Ley 29/1998.

\footnotetext{
${ }^{52}$ Decreto Foral 288/1990, de 25 octubre, de creación del Registro de Entidades Locales de Navarra.

53 Decreto 371/1998, de 10 diciembre regula el Registro de Entidades Locales de Galicia.

${ }^{54}$ Decreto 215/2000, de 19 octubre crea el Registro de Entidades Locales y establece su organización y funcionamiento.

${ }^{55}$ Ley 6/2003, de 9 octubre Ley de Símbolos, tratamientos y registro de las Entidades Locales de Andalucía.

${ }^{56}$ Decreto 10/2004, de 13 febrero crea y regula el registro de Entidades Locales de La Rioja.
} 
La imposibilidad de impugnar este tipo de acuerdos en vía administrativa no se debe tanto al hecho de estar dictados por un órgano administrativo sin superior jerárquico, donde podría caber un hipotético recurso potestativo de reposición, sino por tratarse de disposiciones administrativas de carácter general, las cuales se encuentran exentas de la posibilidad de ser impugnadas en vía administrativa.

En cualquier caso debe mencionarse que dado que la mayoría de los Decretos sobre cambio de denominación municipal aprobados por el Pleno del Consell han sido positivos, apenas ha habido impugnaciones en esta materia, no llegando a la decena los asuntos de este tipo presentados ante el Tribunal Superior de Justicia de la Comunidad Valenciana.

\section{Entidades Locales menores}

El último artículo del Decreto 58/1992, de 13 de abril, del Gobierno Valenciano, por el que se regula el procedimiento para la alteración del nombre de los municipios, preceptúa que el procedimiento en el mismo contenido ha de ser aplicado igualmente a los cambios de nombre de los núcleos de población que constituyan entidades locales de ámbito inframunicipal. Los artículos 47.2.b) y 123.1.e) de la LRBRL determina como competencia del Pleno del Ayuntamiento la iniciativa para la creación y supresión de este tipo de entidades locales supramunicipales, pudiendo ser presentada asimismo por los habitantes de dichos entes territoriales. En la Comunidad Valenciana el procedimiento aprobado para el cambio de denominación municipal ha sido escasamente aplicado a los efectos de proceder al cambio de denominación de las entidades inframunicipales, pues aún se está en un momento inicial en que dichas entidades locales menores están tomando conciencia de sí mismas y se están constituyendo legalmente como tales. De hecho sólo ha habido un cambio de denominación de entidades inframunicipales en el ámbito valenciano, el cual se llevó a cabo junto al del municipio al que las mismas pertenecían. Se trató del Decreto 205/1996, de 5 de noviembre, del Gobierno Valenciano, por el que se aprobaba el cambio de denominación del municipio de Alcalá de Chivert por la forma en valenciano de Alcalà de Xivert, así como el cambio de los topónimos Cap i Corp por Capicorb, y Alcocebre por Alcossebre.

Aunque hoy en día la incidencia del artículo comentado carezca de relevancia, no puede desconocerse que estamos enfrontando un nueva era por cuanto se refiere a los gobiernos locales y al modo de gestión de los servicios públicos en el seno de los mismos. La cercanía en la prestación 
de estos servicios se exige por parte de la ciudadanía, instándose a que ello se realice cada vez de un modo más próximo, de tal forma que las entidades locales inframunicipales, identificadas con los núcleos de población diferenciados del que da capitalidad al municipio, comenzarán a cobrar protagonismo en este nuevo tiempo, reivindicando por ello sus derechos y, entre ellos, el de denominarse conforme el espíritu de sus habitantes lo sienta.

\section{CONCLUSIONES}

1. Uno de los postulados que se desprende de este trabajo es la relación existente entre políticas de normalización lingüística y procedimientos de cambio de denominación de municipios, ello se evidencia por los siguientes motivos:

a) En la mayoría de los Estatutos de Autonomía de las Comunidades Autónomas que cuentan con lengua propia, se hace referencia expresa al hecho de que la denominación oficial de los municipios será la hecha en dicha lengua, o, al menos, que se permite el uso de la misma en dichas denominaciones.

b) En las distintas leyes de normalización lingüística aprobadas existen preceptos especialmente dedicados a revindicar la nomenclatura en la lengua propia de los municipios de la región.

c) Únicamente las Comunidades Autónomas con lengua propia (no todas, pero sólo ellas) han aprobado un procedimiento específico, por ley o decreto, relativo al cambio de denominación de municipios. Además, en la exposición de motivos de esas normas, se hace referencia expresa a que la aprobación de los textos responde a la ejecución de las políticas lingüísticas autonómicas correspondientes.

d) La gran mayoría de cambios de denominación de municipios, observados en cómputo nacional, han respondido a una adaptación del topónimo local a las diversas lenguas propias, suponiendo el cambio de castellano a castellano un porcentaje mínimo de los mismos.

e) Sólo ha habido verdadera incidencia de cambios de denominación de municipios en Comunidades Autónomas con lengua propia, alcanzándose altos porcentajes de alteraciones en ellas, en contraposición a los producidos en el resto de Comunidades Autónomas, donde se han instruido muy pocos expedientes sobre la materia. En este sentido deben tenerse en cuenta, ade- 
más, dos hechos: el primero, es que todavía restan muchos municipios con expedientes sobre cambio de denominación en preparación o susceptibles de ser iniciados; el segundo, se refiere a que territorios como Cataluña cuentan con un gran número de municipios que ya contaban con denominación en lengua catalana, por lo que no ha sido preciso variarla, pero que deben ser considerados a la hora de determinar la verdadera incidencia de la lengua en la nomenclatura de las poblaciones. Esta última afirmación se hace en el sentido de que no sólo el número de cambios de denominación de municipios dan idea sobre la presencia real de la lengua propia en un territorio, sino que, lo verdaderamente importante, más allá de cuantos pueblos varían su nombre de castellano a la lengua vernácula, es saber cuantos reciben su nombre en la misma, independientemente que dicho nombre se le haya dado en la época autonómica o con anterioridad.

2. La Comunidad Valenciana tiene competencia exclusivas en materia de cambio de denominación municipal. Esta competencia se refiere tanto a la aprobación de la normativa aplicable como a la resolución de los expedientes que se presenten.

3. La normativa que regula la competencia y el procedimiento sobre cambio de denominación municipal en la Comunidad Valenciana es la siguiente:

a) Artículo 31.8 LO 5/1982, de 1 de julio, por la que se aprueba el Estatuto de Autonomía valenciano.

b) Artículo 15 Ley 4/1983, de 23 de noviembre, de uso y enseñanza del valenciano.

c) Decreto 58/1992, de 13 de abril, del Gobierno Valenciano, por el que se regula el procedimiento para la alteración del nombre de los municipios.

d) Artículos 14, 22.2, 47.2.d) y 123.1.e) Ley 7/1985, de 2 de abril, reguladora de las bases del régimen local (Supletorio).

e) Artículos 26 al 30 Real Decreto 1690/1986, de 11 de julio, por el que se aprueba el reglamento de población y demarcación de las Entidades Locales (Supletorio).

4. Los expedientes sobre cambio de denominación municipal los inician los propios Ayuntamientos, los instruye la Dirección General de Administración Local, correspondiendo al Conseller de Justicia y Administraciones Públicas, una vez finalizado el mismo, elevar propuesta al Pleno del Consell, el cual resolverá por Decreto. 
5. Ha de modificarse el artículo 26.2 del Real Decreto 1690/1986, para que en él se recoja la misma mayoría que la que aparece en el artículo 47.2.d) de la LRBRL, en su redacción dada por la Ley 57/2003, de 16 de diciembre, de medidas para la modernización del gobierno local.

6. Debe eliminarse del artículo tercero del Decreto 58/1992, la referencia que se hace a la presentación de alegaciones por los interesados en el trámite de exposición pública del expediente, debiendo indicarse que en dicho periodo podrán presentar alegaciones las personas físicas y jurídicas que lo consideren oportuno.

7. Debe eliminarse de la Exposición de Motivos del Decreto 58/1992, las referencias que se realizan a la Dirección General de Política Lingüística.

8. En los expedientes sobre cambio de denominación municipal la norma exige informe del órgano autonómico competente en materia lingüística. Consideramos que ese informe debería emitirse, en los casos de cambio de denominación de castellano a valenciano, o de valenciano a valenciano, por la Academia Valenciana de la Lengua.

9. En los casos de cambio de denominación municipal de castellano a castellano, en los bilingües si se modifica la denominación castellana, y en aquellos que se considere oportuno, debiera ser igualmente preceptivo el informe del Consejo Valenciano de Cultura.

10. Entendemos necesario que el cambio de denominación municipal sea aprobado por la ciudadanía por medio de una consulta popular. Dicha consulta podría tener lugar una vez finalizado el expediente en fase local, antes de ser remitido a la Generalitat, o una vez hubiese finalizado el procedimiento gubernativo y antes de dictar el Decreto correspondiente.

11. Consideramos de interés crear un Registro de Entidades Locales de la Comunidad Valenciana.

12. El procedimiento establecido en el Decreto 58/1992 es también de aplicación a los cambios de denominación de las entidades locales menores, pudiéndose extender su uso a los renombramientos de accidentes geográficos y demás elementos cuya denominación se considere de suficiente relevancia. 


\section{BIBLIOGRAFÍA}

MenÉndez Pidal R.: «Toponimia Prerrománica Hispánica». Ed Gredos. Madrid 1952.

GIMÉNEZ LóPEZ, E.: «Gobernar con una misma ley: sobre la nueva planta borbónica en Valencia». Ed Univ Alicante. Alicante 1999.

González Pérez J. y González Navarro F.: «Comentarios a la Ley de Régimen Jurídico de las Administraciones Públicas y del Procedimiento Administrativo Común. Ley 30/1992». Tomo II. Ed Civitas. Madrid 2004.

García de Enterría E. y Fernández T.R.: «Curso de Derecho Administrativo». Tomo II. Ed Civitas. Madrid 2002.

Generalitat Valenciana: «Denominación Oficial de los Municipios de la Comunidad Valenciana». Ed Generalitat Valenciana. Valencia 1991. 


\section{Jurisprudencia}

